\title{
Impacts of Digital Natives on Technology Acceptance: A Conceptual Analysis
}

\section{Tim Hamelmann}

University of Duisburg-Essen

Essen, Germany

Email: tim.hamelmann@uni-due.de

\section{Andreas Drechsler}

School of Information Management

Victoria University of Wellington

Wellington, New Zealand

Email: andreas.drechsler@vuw.ac.nz

\section{Abstract}

We seek to identify the impacts Digital Natives (DN) - as the first generation that has grown up with new digital technologies such as the Internet from their childhood - have on technology acceptance (TA) by investigating the effect of DN' specific traits, abilities, and experiences on TA factors and variables. We conduct two literature reviews: the first about TA factors and variables and the second about DN and generational differences. We find that some TA factors and variables that prior research has pointed out as significant are likely to change in importance: DN do not question the use of technology itself and may be at least partially familiar with it but simultaneously have higher demands for the quality and usefulness of technology. Researchers can draw on our findings to validate them empirically in the future or problematize the current state of TA research. Practitioners can apply our findings to develop information systems that DN find attractive to use.

Keywords technology acceptance, information systems acceptance, digital natives, digital immigrants, generational differences 


\section{Introduction}

Today, information systems (IS) are an essential component of every enterprise's architecture. However, an IS cannot be successful if the users do not use it (Davis et al. 1989). Thus, technology acceptance (TA) is an important aspect for the success of IT investments, which is why a plethora of prior research has addressed TA (Marangunić and Granić 2014). Davis et al. (1989) have published their initial Technology Acceptance Model (TAM) almost 30 years ago and it has become the most widely used theory IS researchers draw on to investigate the human behaviour with respect to TA (Bradley 2012), despite numerous criticisms directed at TAM itself and TA research in general (Bagozzi 2007; Lee et al. 2003).

Not covered by these criticisms, however, is generation research's tenet that human behaviour does not stay invariant over generations (Hurrelmann and Albrecht 2014). Generation research tries to group people by their age or life circumstances in order to assign them to a certain generation. It also tries to elucidate specific traits of these generations and makes assumptions about their behaviour and thinking in order to identify generational differences and societal changes. In generation research, Digital Natives (DN) is a term used to describe all people that grew up with new digital technologies (e.g., the Internet) and therefore "process information fundamentally different from their predecessors" (Prensky 2001a, p. 1). Prensky also introduced a complementary term - the Digital Immigrants (DI) - for people during whose life technologies such as the Internet have just been established and who had to learn how to deal with them (Günther 2007; Prensky 2001a). DN represent a technology-savvy generation that appreciates using digital technology (Ferri-Reed 2014). It is normal for them to use digital technology to solve problems, to manage their everyday life, and to communicate with other people. The literature posits that this generation is fundamentally different from previous generations, especially with respect to their acceptance of digital technology. Prensky (2001a) speaks of a 'digital language' which DN learn early in their life, while DI had to learn it later and always retain a 'DI accent'. Some researchers even postulate the end of technology denial in this new generation (Solnet et al. 2012).

Therefore, it is at least questionable if prior TA findings - which are mainly based on the DIs' behaviour and also make up quite a substantial body of IS research - will retain their validity in the future. More fundamentally, as digital technology may even become part of DN's individual identities (Carter and Grover 2015), the question arises whether the traditional assumptions of TA research (e.g. individuals encounter unfamiliar technology) are still valid. To investigate this issue further and to contribute to closing the gap between IS TA research of the past and upcoming generational change, we set out to answer the following three research questions:

RQ1: What are DNs' characteristic personality traits and attitudes?

RQ2: What factors and variables influence TA that could be affected by DNs' traits and attitudes?

RQ3: How do the identified DNs' traits and attitudes affect these TA factors and variables as well as the underlying assumptions, and what are implications for future TA research?

We conduct two literature reviews to answer our research questions, which follow Webster and Watson's (2002) and Okoli's (2015) suggestions. The first one in Section 2 identifies DNs' personality traits and attitudes by searching for different terms from generation research such as "Digital Natives", "Generation Y", or "Millennials" across databases that span disciplines such as IS research, computer science, business administration, management, psychology, and sociology. Search results that were not conductive to be linked to TA research in the organisational context were not pursued further.

For the second one, we first draw on a literature review paper that already summarizes major parts of TA research in a comprehensive model (Sorgenfrei et al. 2014). We then extend their literature coverage in Section 3 by searching for topics like DN, generation issues, or social aspects in connection with TA, in order to gain further insight into TA factors that are related to personality traits and attitudes. Here, TA theories that do not contain factors based on personality, emotion, or the organizational situation were excluded from our scope.

Following Rowe's (2014) suggestions, we then match our synthesized findings in the form of the variables and factors that influence TA and the DNs' personality traits and attitudes with each other and critique the former against the latter in Section 4. We then discuss our findings and the implications of considering DN for future TAM research and TA theorizing in Section 5. We conclude and give a brief outlook towards future research in Section 6.

\section{Digital Natives - Traits, Personality, and Behaviour}

This section synthesizes the results of our literature review about DN and their traits across several areas we identified to be emphasized in the literature. We start with aspects related to the individual and move 
on further to work environments, and DNs' roles in and general fit to organizations. Note that the term 'Digital Native' is related to other terms from generation research: 'Generation Y', 'Millenials', 'Generation Me', or 'Net Generation' (Appel 2013; Butler and Sauser 2013; Hurrelmann and Albrecht 2014; Parment 2013; Twenge 2010). However, the terminology and birth years to delimit these generations from others vary among authors. For this reason, we follow Appel (2013) and use the term DN to highlight this group's most important trait: their changed way to use technology, irrespective of their exact birth years. Table 1 summarises key DN characteristics from the literature.

\begin{tabular}{|c|c|}
\hline \multicolumn{2}{|c|}{ Digital Natives... } \\
\hline $\begin{array}{l}\text { and } \\
\text { technology }\end{array}$ & $\begin{array}{l}\text { - } \quad \text { are more well-educated and technophile than previous generations (Han and Su 2011). } \\
\text { are more impatient and have a higher need of instant response (Andone et al. 2006; Butler } \\
\text { and Sauser 2013). } \\
\text { have their strategic thinking shaped by technology being a key part of their personal and } \\
\text { social life (Andone et al. 2006). } \\
\text { have mastering digital technology as a natural, special, distinctive, and sustainable skill that } \\
\text { encompasses learning-by-doing and internet searches (Prensky 2001a). }\end{array}$ \\
\hline $\begin{array}{l}\text { and } \\
\text { information } \\
\text { processing }\end{array}$ & $\begin{array}{l}\text { - } \quad \text { value instant access to information, preferably visualised (Prensky 2001a). } \\
\text { - } \quad \text { like to receive information little by little (Han and Su 2011). } \\
\text { - } \quad \text { san process information more quickly than previous generations (Butler and Sauser 2013). } \\
\text { pieces of information (Ziehe 2013). } \\
\text { - } \quad \text { may have difficulty focusing on a single task but can cope with information overload and a } \\
\text { - } \quad \text { telatile and fast-changing world (Ziehe 2013). }\end{array}$ \\
\hline $\begin{array}{l}\text { and } \\
\text { personality } \\
\text { traits and } \\
\text { values }\end{array}$ & $\begin{array}{l}\text { - } \quad \text { live in a globalized world and face higher pressure and increasing uncertainty than previous } \\
\text { generations (Hurrelmann and Albrecht 2014). } \\
\text { - } \quad \text { tend to seek at least a small amount of security and stability (Günther 2007). } \\
\text { tend to be alert, attentive, aware of their problems, concentrated, and like to have things } \\
\text { under control (Tapscott 1998). } \\
\text { have a higher IQ than DI on average (Günther 2007) and tend to be more well-educated } \\
\text { (Han and Su 2011; Hurrelmann and Albrecht 2014). } \\
\text { have an inquisitive mind due to having grown up in an environment in which they were } \\
\text { allowed to ask questions, to provoke, and to express individual opinions (Tapscott 1998). } \\
\text { - } \quad \text { tend to be very self-confident, and more selfish and even narcisstic compared to previous } \\
\text { generations (Ahn and Ettner 2014; Twenge and Campbell 20o8). } \\
\text { - } \quad \text { have therefore good at critical thinking and being more outspoken than DIs (Tapscott 1998). } \\
\text { problems and uncertainty earlier in life (Tapscott 1998). } \\
\text { - may have experienced taking different roles early in their life (for example in chatrooms or } \\
\text { online games) but are also less able to reflect their own behaviour and to learn from their } \\
\text { experiences (Prensky 2001b). } \\
\text { perceive themselves to be different from DI (Butler and Sauser 2013). }\end{array}$ \\
\hline $\begin{array}{l}\text { and work } \\
\text { attitudes and } \\
\text { behaviour }\end{array}$ & $\begin{array}{l}\text { - } \quad \text { value a good work-life-balance including free time more highly than DI (Twenge 2010). } \\
\text { - } \quad \text { seek to find more satisfaction, meaningfulness, and fulfilment in their work than previous } \\
\text { generations (Günther 2007; Hurrelmann and Albrecht 2014; Parment 2013). } \\
\text { - } \quad \text { may impatient and live in a “quick-payoff world" (Prensky 2001b). } \\
\text { - } \quad \text { tend to be satisfied with their job and are loyal until they find a better offer (Hurrelmann } \\
\text { and Albrecht 2014; Kowske et al. 2010; Twenge 2010). } \\
\text { - } \quad \text { are flexible, able to adapt to change quickly (Günther 2007), and innovative (Tapscott 1998). } \\
\text { They tend to ask "Why not?" rather than "Why?" in the face of change. } \\
\text { appreciate diversity and collaboration (Han and Su 2011) and care less about gender and } \\
\text { - } \quad \text { pocial differences (Tapscott 1998) than previous generations. } \\
\text { - tend collaborative decision-making and teamwork (Hernaus and Vokic Pološki 2014) but } \\
\text { - to assess other persons by their contribution and the ideas they bring in and thus } \\
\text { decrease classic barriers of team work (Tapscott 1998). } \\
\text { take electronic collaboration for granted (Andone et al. 2006; Solnet et al. 2012). } \\
\text { have a low affinity to assume management responsibility positions (Twenge 2010). }\end{array}$ \\
\hline $\begin{array}{l}\text { and } \\
\text { organisa- } \\
\text { tional }\end{array}$ & $\begin{array}{l}\text { - } \quad \text { want to work in highly motivated, committed and goal-oriented teams (Martin 2005). } \\
\text { value friendship and good relationships with their colleagues more highly than previous } \\
\text { generations (Solnet et al. 2012) and are less rivalry-oriented (Tapscott 1998). } \\
\text { - can adapt to continuously changing teams over their working life (Günther 2007). }\end{array}$ \\
\hline
\end{tabular}




\begin{tabular}{|c|c|}
\hline $\begin{array}{l}\text { structures } \\
\text { and culture }\end{array}$ & $\begin{array}{l}\text { - } \quad \text { may have trouble working in multi-generational teams (Anantatmula and Shrivastav 2012). } \\
\text { may not necessarily fulfil tasks without asking questions as it is necessary for them to } \\
\text { understand what they do and why they do it. They may simply say "no" if they are not } \\
\text { sufficiently convinced (Parment 2013). } \\
\text { value employee engagement, transparency, and an emotional and intellectual openness } \\
\text { more highly than DI, and managers must be willing to explain tasks and answer questions } \\
\text { (Parment 2013; Solnet et al. 2012; Tapscott 1998). } \\
\text { - } \quad \text { require a more emotional component to their management (Günther 2007). } \\
\text { - } \quad \text { want to be independent and work on their own authority (Czichos 2014). } \\
\text { - } \quad \text { want to keep learning things during their work life (Hurrelmann and Albrecht 2014) or they } \\
\text { - may become easily bored (Solnet et al. 2012). } \\
\text { prefer interactive and physically or virtually connected learning opportunities (Andone et } \\
\text { al. 2006). }\end{array}$ \\
\hline
\end{tabular}

Table 1. Key characteristics of Digital Natives

\section{A Technology Acceptance Analysis Framework}

In this section, we now synthesize the current state of TA research into an analysis framework, which we use subsequently to contrast antecedents and contextual factors for TA with DNs' characteristics.

There is a considerable amount of literature reviews on TA research (Bradley 2012; Hwang et al. 2015; Lee et al. 2003; Legris et al. 2003; Marangunić and Granić 2014; Sorgenfrei et al. 2014; Venkatesh et al. 2003; Williams et al. 2009). Our challenge therefore is finding an adequate focus on relevant aspects for our research scope. After careful consideration, we draw on Sorgenfrei et al.'s (2014) TA reference framework, which synthesizes different TA and adoption-related research streams into one comprehensive framework. Their framework's scope encompasses the most relevant theories for TA: Theory of Reasoned Action, Theory of Planned Behaviour, the Technology Acceptance Model (TAM), Innovation and Diffusion Theory, Model of Computer Self-Efficacy, Unified Theory of Acceptance and Use, IS Continuance Model, IS Success Model, and Task-Technology-Fit Model. However, we need to tailor their framework further to make it suitable as an analysis framework to answer our RQ2 and RQ3.

First, Sorgenfrei et al.'s (2014) framework distinguishes between different acceptance stages. However, for us, the preconditions and beliefs are most relevant because they are based on personality traits and social aspects, which then can be linked to DNs' traits. Therefore, we omit any distinction between different acceptance stages. Second, their framework distinguishes five categories of antecedents and contextual factors for TA: task-related characteristics, technology-related characteristics, individual characteristics, interpersonal factors, and situational factors. The category of task-related characteristics is very distant from social aspects that can be matched with generational traits. Therefore, we do not consider antecedents and contextual factors from this category. Third, our literature review revealed relevant factors that were not part of the original framework, and we add these to our framework.

Figure 1 shows the adapted framework that we will subsequently rely on and call the technology acceptance framework (TAF). We highlight additions over Sorgenfrei et al.'s (2014) framework in italics.

\section{Matching Digital Natives' Characteristics and Behaviour with Technology Acceptance Findings}

In this section, we now contrast the results of the literature review on DNs from Section 2 with the elements of the TAF from Section 3 to identify the effects DN have on TA.

\subsection{Technology-related impacts}

First, we analyse the DNs' impact on their individual beliefs and, subsequently, TA with respect to the technology-related characteristics contained in the TAF. Technology-oriented characteristics focus on the properties of the particular IS that to be accepted.

Complexity of technology. Complexity is seen as a characteristic of the technology as perceived by its users (Aizstrauta et al. 2015). As DN are said to have an increased IQ and are well educated, one can expect them to generally fulfil the cognitive requirements to understand a reasonably complex IS. It should also be helpful for the TA process that they are curious, open-minded, process information very 


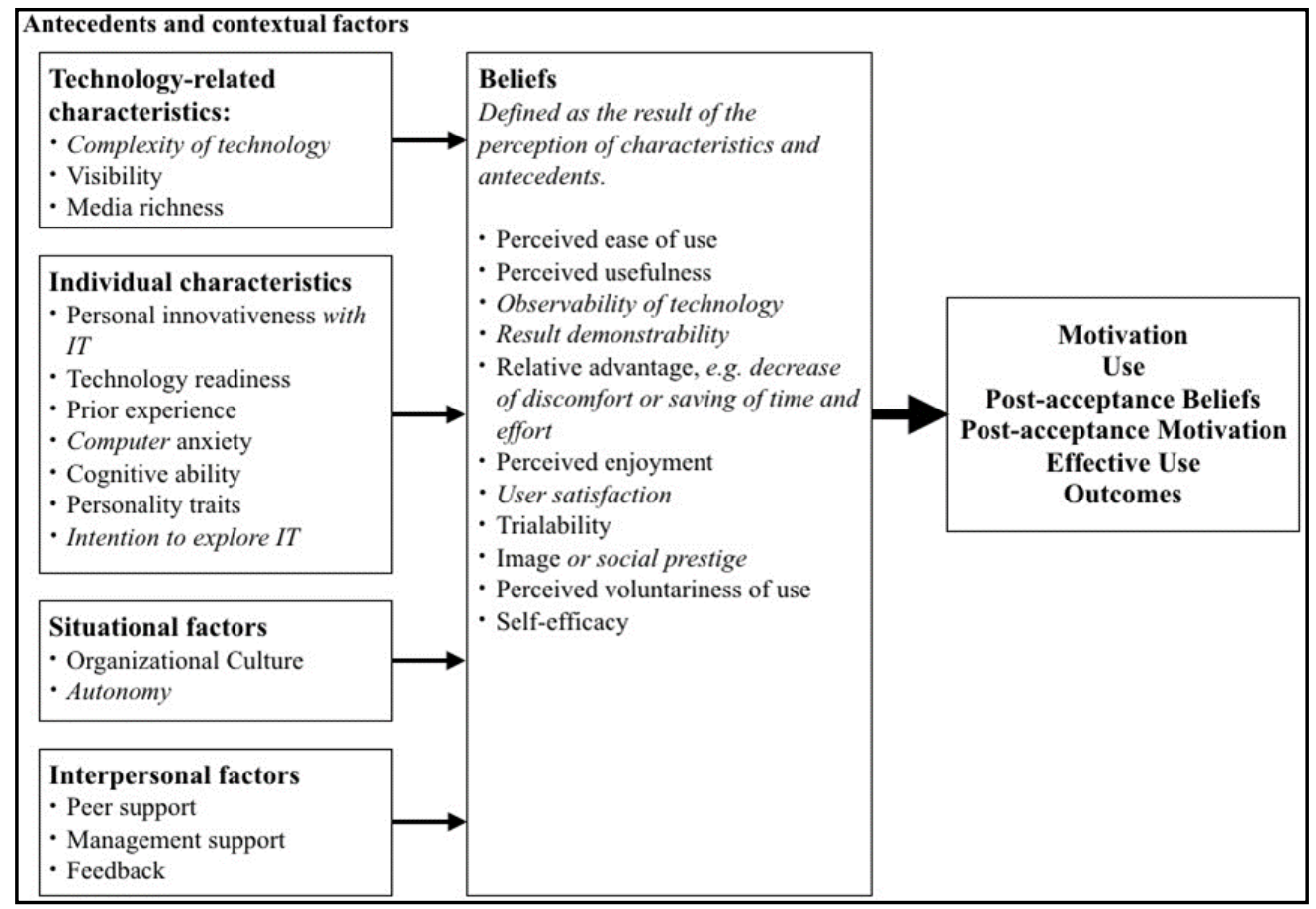

Figure 1. Sorgenfrei et al.'s (2014) TA reference framework adapted for our purposes

quickly, and tend to like exploring IS learning-by-doing. However, a prerequisite for this is that the IS needs to be easy to use - especially with respect to the possibility to explore the system without reading any instructions in a manual. This is important because DN are also attentive and think critically with a questioning attitude. While DI may have learned to arrange themselves with less-than-intuitive user interfaces or workflows, DN expect seamless interactions with technology and can therefore be expected to put up higher and more principled resistance against IS complexity they perceive to be unnecessary. Due to their innovative thinking, they can also be expected to be more willing participants in efforts to redesign and improve IS that they use further. A disadvantage may be that DN strew their attention and maybe perform other tasks in multitasking while they explore a new IS. One option to keep their attention could be enjoyment. Therefore, designing an IS so that using it can be perceived as 'fun' may foster DNs' TA, despite the IS' complexity.

Visibility. This factor refers to the degree to which a novel technology is visible or discernible as such in an organization (Karahanna et al. 1999). DN not only value transparency but they also seek to understand what they do and why they do it. Consequently, they will carefully consider to use or not to use an IS and the benefits of using it. Therefore, one would expect that making an innovative and relevant nature of an IS visible to DN would be particularly conductive to foster their TA.

Media richness. To catch the DNs' attention, an IS should contain graphics and other visual elements instead of text wherever it makes sense - especially for important data or information the IS displays (Tilvawala et al. 2011). Because DN direct their attention to graphical elements first, their implementation may contribute to avoid the DNs' habit of strewing their attention and to receive information little by little, so that they do not miss out on important data or information. Due to the fact that DN do not always succeed in reflecting their own behaviour this seems to be easier than trying to make DN change the way they process the information that is displayed by the IS.

Taken together, these implications mean that we would expect DN to appreciate IS with particular characteristics over others. In other words, the overall impact of DNs' characteristics on TA seems to be highly dependent on the characteristics of the IS in question, such as its hedonic value or media richness.

\subsection{Impacts of individual characteristics}

Individual characteristics refer to individual traits such as personality traits, experiences, and attitudes. Obviously, these characteristics are of major importance for our analysis because they facilitate establishing a direct link between DNs' personality traits and attitudes and TA (Agarwal and Prasad 1998; Ahuja and Thatcher 2005; Carter et al. 2012; Immonen and Sintonen 2015; Nambisan et al. 1999; Petter et al. 2013). 
Personality traits. Many of DNs' common personality traits foster TA. They are curious, openminded, innovative, flexible, and used to adapt to change.

Cognitive abilities. DN tend to be well-educated and are said to have an increased IQ compared to previous generations. Therefore, they should possess the necessary the cognitive abilities to operate unknown IS, which contributes to increased TA.

Prior experience. DN use technology extensively, not only in their work life, but also in their free time and their social life. Many DN learn to deal with IT at home and in school before they start their working life, and therefore already possess ample prior experience in using and learning new technology.

Computer anxiety. The previously discussed aspects combined with high levels of self-confidence and a willingness to learn lead to an overall low level of computer anxiety for DNs.

Intention to explore IT. DN are curious, they like to experience new technology, are self-reliant, and like learn to deal with technology learning-by-doing. Therefore, they possess a predisposition towards exploring new technology.

Personal innovativeness. DN have an innovative attitude so they tend to explore technology especially in order to find new ways to deal with their tasks in a more efficient and enjoyable way.

Technology readiness. In sum, we would expect that the DNs' abilities and personality traits make them technology-ready and therefore foster TA.

\subsection{Impacts of the organizational culture and autonomy}

Situational factors represent the outer circumstances and the work environment. Ahuja and Thatcher (2005) emphasize that work environment characteristics can benefit TA.

Organizational culture. Jordan and Burn (1997) and Dasgupta and Gupta (2005) highlight the importance of the organizational culture for successful TA. There are several general factors that foster TA within an organization: high motivation, high commitment, collaborative decisions, and an innovative climate. Here, DN demand a transparent organizational culture with good relationships with colleagues, and a flat hierarchy. Their collaborative decision-making can increase network effects as DN tend to accept IS that their colleagues accept as well. Simultaneously, DN struggle with hierarchies and a command-and-control culture. For TA, this points towards a particularly important role of the organizational culture.

Autonomy. DN value work autonomy. They want to get tasks done but also want to decide on their own when and how they fulfil them. While a high autonomy can foster individual innovativeness with technology, this DN trait makes managerial control over TA more difficult and may ultimate lead to selfreinforcing positive or negative circles among a peer group of DN users who evaluate the pros and cons of adopting a new technology among themselves while being resistant to external influence by change agents, for instance.

Especially autonomy therefore seems to be a factor of particular importance for TA in the context of DN, while the factors of the organizational culture that DN appreciate also benefit TA and thus one would expect these factors to be aligned with increased TA.

\subsection{Impacts of interpersonal factors}

Interpersonal factors concentrate on the relationships to others as well as on communication and interaction between people and belong to the most important factors for potential technology adopters and users (Karahanna et al. 1999). In particular, positive relationships to managers and co-workers and other social aspects like the team composition are important and should be considered when implementing a new IS (Magni and Pennarola 2008).

Peer support. Peer support refers to the degree to which users receive support from their peers for using a particular technology (Petter et al. 2013). Niehaves et al. (2012) emphasize that TA can be increased by network effects in organizations which can be achieved by a strong peer support. Park et al. (2011) point out that facilitating conditions to benefit TA are much more effective on a group-level rather than on an individual level. Here, DN value good relationships to colleagues and prefer collaborative decision-making and working. They are not overly competitive and they assess people by their contribution. All these factors foster a constructive work climate, peer support, and thus TA as well. However, managers should also be aware of possible problems like narcissism, generational differences in teams, and selfish attitudes among DN. 
Management support. DN demand their managers to be empathic and engaged, but not too overbearing since they demand work autonomy and flat hierarchies, while they are not too comfortable with taking responsibility themselves. This leads to an almost paradoxical situation for managers who may have to find the right balance of attention and 'benign neglect' for their DN employees during TA.

Feedback. Answering their questions quickly and giving them instant feedback can be a particularly good way how managers can support TA for DN.

In sum, the interpersonal factors do not only remain important for TA, but the DNs' traits point to a certain configuration of interpersonal factors that may be particularly conductive to TA for DN.

\subsection{Impacts of individual beliefs}

As mentioned before all the antecedents and contextual factors lead to particular individual beliefs. These beliefs can be seen as a result of preconditions and shape the foundation for the whole process of TA and all its stages.

Perceived ease of use. Compared to DI, one can expect DN to perceive using a given IS to be easier, due to their prior experience, high extent of technology use, and good education. DN have been using many different IS over the course of their life, so they know different user interfaces and handling concepts. However, they may also be particularly critical towards not well-designed IS or IS that do not fit their information seeking and processing behaviour. As outlined among the technology-related factors above, one can expect IS design characteristics to influence DNs' perception of ease-of-use.

Perceived usefulness. DN work goal-oriented and value efficiency. Therefore, we can expect an IS' usefulness to be very important to them. When they use or even just try out a new piece of technology, they seek a quick pay-off, think strategically, and handle time resources well. Consequently, we would expect the perceived usefulness to continue to play an important role for TA, perhaps even more so than for DI. Moreover, it is likely that DNs' particular information seeking and processing behaviour influences their perception of usefulness compared to DI.

Observability of technology. This factor refers to how visible technological benefits are to potential users (Aizstrauta et al. 2015). DNs are inquisitive and curious, especially about technology, and they also process information quickly, with a shortened attention span. To foster TA, IS therefore need to 'advertise' their benefits to DN users quickly to capture their attention and convince them that they are indeed useful for them.

Result demonstrability. DNs highly value peer-support and a transparent organizational culture, and they are used to sharing information quickly with their peers. One would therefore expect for result demonstrability to play a noticeable role among DN in affecting TA.

Relative advantages. This factor comprises the extent to which technology can decrease its users discomfort or save them time and effort (Aizstrauta et al. 2015). As said before, DN work efficiently, goal-oriented, and can handle time resources well. Thus, they will highly value savings of time and effort. Therefore, we would expect that DNs value relative advantages that new technology brings at least as high as DI, if not even higher, as prerequisites for TA.

Perceived enjoyment. DN are curious and want to learn new things. So exploring a new IS could be fun for them. They like enjoyment during work, especially because they seek sense and fulfilment in their work life and not a job with boring tasks. Compared to DI, one could expect DNs placing higher value of the hedonic nature (Van der Heijden 2004) of work-related IS, and therefore for perceived enjoyment to play a bigger role for TA.

User satisfaction. Compared to DI, we would expect user satisfaction to play a more important role for DN, as it is influenced by other factors which also could play a more important role such as perceived usefulness or perceived enjoyment. And even after an initial acceptance of an IS, user satisfaction should be monitored throughout the post-adoption phase because DN have a questioning attitude and will criticize the IS or even their managers if they are not satisfied. For instance, a volunteer use could foster satisfaction, too.

Trialability. This factor refers to the degree to which potential users can experiment with a new technology before an adoption decision (Karahanna et al. 1999). DN really like to explore new technology and they prefer doing this learning-by-doing. Therefore, they will obviously require trialability of a new IS, which also benefits their habit to explore things little by little and autonomously. Furthermore, they are curious and want to keep learning, so trying out new things without any coercion will make them happy and the increase the chance of TA. To support this process, managers should enhance the 
perceived voluntariness of use, which is a new separate construct we would like to propose in the context of DN to be examined separately.

Image or social prestige. These factors capture how adoption and usage of a technology is compatible with a potential user's social and cultural values and beliefs and how potential users believe it to enhance their social status (Aizstrauta et al. 2015; Karahanna et al. 1999). As opposed to the previous factors, image or social prestige are candidates for factors that may have lost some of their meaningfulness for DN users. DN want to have good relationships to colleagues and do not strive for internal rivalry. They are also more self-confident and not afraid to say what they think and to bring in new ideas. Thus, we would expect DN to care less about these factors during their consideration of new technology than DI.

Self-efficacy. This factor addresses how self-confident users feel about their ability to use a particular technology or technology in general (Petter et al. 2013). Many of the previously discussed factors point out that DN will believe in their abilities to use an IS in an efficient and in the intended way. Examining DNs' self-efficacy's role in TA therefore may yield less interesting results than for DI.

\section{Discussion and Limitations}

Our matching of DNs' generational traits with the current state of TA research indeed indicates that several factors influencing TA may have a changed importance in the future for DN than for DI.

On the technological side, the inherent system quality and perceived usefulness, visibility and observability of results and benefits, the system's hedonic value, trialability, and media richness are factors that we posit to play an increased role contributing to TA. These factors highlight that the type of IS that is investigated in a TA study matters. Is it - simply put - an IS developed by DI for DI, which is now to be used by DN? We would presume that the results would be strikingly different if one investigated an IS developed by DN for DN, which is being used by the same group of DN in the same context. On the social side, DNs particularly value the right organizational culture, autonomy, peer support, and feedback, and we posit that these factors increase in importance for TA as well.

For a second group of TA factors, the implications for TA appear more nuanced. While the DNs' increased technology-savviness allows them to handle complex IS more easily, their pragmatic attitude contributes to the rejection of complexity they perceive as unnecessary. For managerial support, the right type of support seems to matter - support that fosters the aforementioned social factors, is ready to supply answers to DNs' critical questions, and refrains from taking a too strong control attitude. The challenge for TA research here will be to (re-)operationalize existing constructs into items that can adequately capture these nuances. In particular, the discussion in the previous section highlights that a mono-dimensional measurement of factors from first two groups may not be sufficient anymore - e.g. one can consider splitting use into hedonic versus instrumental use, or managerial control into a beneficial and a restrictive component.

A third group of TA factors may be of lesser importance in the future - particularly many individual characteristics such as computer anxiety, prior experience, intention to explore technology, technology readiness, self-efficacy, or image / social prestige. Moreover, given that a diminishing importance of at least some of these factors can be empirically supported in the future, the rise of DN in the workforce will at least help simplify TA research models and allow researchers to put the more important and more nuanced factors under closer scrutiny. Simultaneously, given the ongoing technological innovation, even today's DNs will encounter new types of digital technology (e.g. wearables, cyborg technologies) they will be initially entirely unfamiliar with based on their upbringing. Therefore, we posit that TA research will keep its general relevance although its emphasis may need to shift to distinguish familiar from unfamiliar aspects of a new technology in case it is not of a fundamentally different technology type.

We can also contribute several practical contributions as advice for information systems designers and managers concerned with designing or introducing information systems into organizations with DN:

1. Information systems for DN should be easy to use and designed in accordance with their demand of media richness, quick information processing, and enjoyable use.

2. Managers and change agents should carefully highlight the usefulness of an IS, and be prepared for DNs' critical attitude and relentless questioning.

3. Giving DN work autonomy, trialability and the possibility to learn and evolve can contribute to technology acceptance more so than for DI.

4. Beyond TA, DN generally prefer an organizational culture that fosters good relationships between colleagues, innovativeness, and flat hierarchies. 
Of course this advice will not a guarantee a successful acceptance of an IS, as individual DN - like DI are not all the same and situational factors still play a big role. Therefore, managers still have to know their employees, find out about their particular needs, and introduce new IS accordingly. Our four managerial implications above can therefore only inform managerial and IS design decisions.

However, our findings also come with several limitations, some of which are inherited from generation research. A central problem of research about generational differences is the lack of reliable data. While there are a lot of surveys and studies, it is difficult to put them into context. There is simply little comparable and reliable data available about previous generations. Moreover, it is difficult to ascribe particular behavioural or attitude changes to a different generations, because those could also be consequences of general societal changes that affect all generations (Deal et al. 2010). We tried to mitigate this issue by relying not on birth years, but on the use of and familiarity with technology to delineate DN from DI, and by relating the differences to technological influences. Moreover, there are voices that DN-related research is somewhat of a hype and, in sum, too unreliable to truly identify differing traits and values (Bennett et al. 2008; Deal et al. 2010; Matthes and Fülbeck 2014). For instance, there are indications that the extent of 'digital nativeness' of an individual depends on the extent of the media exposure in their household and therefore not all millennials are DN (Helsper and Eynon 2010). Furthermore, there may be different 'sub-generations' among the DN - first those that have grown up with a computer, then those that have experienced the internet right from the earliest ages, and lastly those that do not know a world without smartphones. Finally, it is difficult to study DNs' workplace behaviour since many DNs have not fully arrived in the workplace yet. Interestingly, the tendency in IS to rely on student samples may have inadvertently helped to already incorporate DN beliefs and attitudes into TA research, but, again, current TA research does not distinguish DN and DI.

We also inherit common TA research limitations. For instance, most TAM studies focus on a single IS in a specific context at a single point in time (Lee et al. 2003). Thus, generalizability across time and other IS is questionable. There are also doubts about the general accuracy of much TA-related research (Bagozzi 2007). Moreover, we relied on one particular TA framework as a foundation for our TAF (Sorgenfrei et al. 2014). While their model is reasonably comprehensive, it does not cover TA research in its entirety. While our additional literature review may have compensated for this to a certain extent, we are far from claiming complete coverage. Moreover, the different theories underlying the integrated perspectives have different assumptions, perspectives, and boundaries, and the corresponding findings may therefore be incommensurable. Lastly, reducing the findings of generational as well as TA research to their essence carries the danger of over-simplification and reductionism.

\section{Conclusion and Outlook}

We identified characteristic DN personality traits and analysed them with respect to implications for factors affecting technology acceptance. While we could not confirm the postulation that DN will indeed end the denial of TA (Solnet et al. 2012, p. 47), our findings highlight that DNs' particular traits, abilities and attitudes may nevertheless have a considerable effect on the acceptance of IS and other technology. Investigating whether our conceptual findings and postulations indeed hold true empirically, how the more nuanced consideration of some factors can be empirically operationalised and integrated into the established type of TA research models, and whether some established factors are indeed of lesser importance for DNs' TA all remain tasks for future research. These tasks, however, may be required to keep TA research findings up-to-date in the light of generational change. Moreover, future TA research can benefit from more expanded perspectives that address the extent of a technology novelty (just a new web app for a routine purpose or a fundamental new technology type such as cyborg technologies?) or acknowledge that some digital technologies may even have become part of DI's identity and self.

\section{References}

Agarwal, R., and Prasad, J. 1998. "A Conceptual and Operational Definition of Personal Innovativeness in the Domain of Information Technology," Information Systems Research (9:2), pp. 204-215.

Ahn, M. J., and Ettner, L. W. 2014. “Are Leadership Values Different across Generations?,” Journal of Management Development (33:10), pp. 977-990.

Ahuja, M., and Thatcher, J. 2005. "Moving Beyond Intentions and Toward the Theory of Trying: Effects of Work Environment and Gender on Post-Adoption Information Technology Use.," MIS Quarterly (29), pp. 427-459.

Aizstrauta, D., Ginters, E., and Eroles, M.-A. P. 2015. "Applying Theory of Diffusion of Innovations to Evaluate Technology Acceptance and Sustainability," Procedia Computer Science (43), ICTE in Regional Development, December 2014, Valmiera, Latvia, pp. 69-77. 
Anantatmula, V. S., and Shrivastav, B. 2012. "Evolution of Project Teams for Generation Y Workforce," International Journal of Managing Projects in Business (5:1), pp. 9-26.

Andone, D., Dron, J., and Pemberton, L. 2006. A Dual Device Scenario for Digital Students - DIMPLE, presented at the IADIS International Conference on Cognition and Exploratory Learning in Digital Age (CELDA 2006).

Appel, W. 2013. Digital Natives: Was Personaler über die Generation Y wissen sollten, Wiesbaden: Springer Fachmedien Wiesbaden.

Bagozzi, R. P. 2007. "The Legacy of the Technology Acceptance Model and a Proposal for a Paradigm Shift.," Journal of the Association for Information Systems (8:4), p. 3.

Bennett, S., Maton, K., and Kervin, L. 2008. "The 'Digital Natives' Debate: A Critical Review of the Evidence,” British Journal of Educational Technology (39:5), pp. 775-786.

Bradley, J. 2012. "If We Build It They Will Come? The Technology Acceptance Model," in Information Systems Theory, Springer, pp. 19-36.

Butler, D. D., and Sauser, W. I. 2013. "Millennials Break Out as the Me Generation: Their Attitudes, Expectations and Fears," in Managing Human Resources for the Millennial Generation, W. I. Sauser and R. R. Sims (eds.), IAP, pp. 23-52.

Carter, M., and Grover, V. 2015. "Me, My Self, and I(t): Conceptualizing Information Technology Identity and Its Implications," MIS Quarterly (39:4), pp. 931-957.

Carter, P. E., Thatcher, J. B., Chudoba, K. M., and Marett, K. 2012. "Post-Acceptance Intentions and Behaviors: An Empirical Investigation of Information Technology Use and Innovation," Journal of Organizational and End User Computing (24:1), pp. 1-20.

Czichos, R. 2014. Erfolgsfaktor Change Management: Den Wandel im Unternehmen aktiv gestalten und kommunizieren, (1. Aufl.), Freiburg ua: Haufe.

Dasgupta, S., and Gupta, B. 2005. "Role of Organizational Culture in Internet Technology Adoption: An Empirical Study," AMCIS 2005 Proceedings.

Davis, F. D., Bagozzi, R. P., and Warshaw, P. R. 1989. "User Acceptance of Computer Technology: A Comparison of Two Theoretical Models," Management Science (35:8), pp. 982-1003.

Deal, J. J., Altman, D. G., and Rogelberg, S. G. 2010. "Millenniais at Work: What We Know and What We Need to Do (If Anything)," Journal of Business and Psychology (25:2), pp. 191-199.

Ferri-Reed, J. 2014. "Building Innovative Multi-Generational Teams," Journal for Quality \& Participation (37:3), pp. 20-22.

Günther, J. 2007. Digital natives \& digital immigrants, Innsbruck ua: Studien-Verl.

Han, D., and Su, X. 2011. "Managing Generation Y: Recruiting and Motivating," in 2011 International Conference on Management and Service Science (MASS), , August, pp. 1-4.

Helsper, E. J., and Eynon, R. 2010. "Digital Natives: Where Is the Evidence?," British Educational Research Journal (36:3), pp. 503-520.

Hernaus, T., and Vokic Pološki, N. 2014. "Work Design for Different Generational Cohorts Determining Common and Idiosyncratic Job Characteristics," Journal of Organizational Change Management (27:4), pp. 615-641.

Hurrelmann, K., and Albrecht, E. 2014. Die heimlichen Revolutionäre: Wie die Generation Y unsere Welt verändert, Weinheim: Beltz.

Hwang, Y., Al-Arabiat, M., and Shin, D.-H. 2015. "Understanding Technology Acceptance in a Mandatory Environment A Literature Review," Information Development 32(4), pp. 1266-1283.

Immonen, M., and Sintonen, S. 2015. "Evolution of Technology Perceptions over Time," Information Technology \& People (28:3), pp. 589-606.

Jordan, E., and Burn, J. 1997. "Information Systems Acceptance: A Consequence of Cultures," PACIS 1997 Proceedings.

Karahanna, E., Straub, D. W., and Chervany, N. L. 1999. "Information Technology Adoption Across Time: A Cross-Sectional Comparison of Pre-Adoption and Post-Adoption Beliefs," MIS Quarterly (23:2), pp. 183-213.

Kowske, B. J., Rasch, R., and Wiley, J. 2010. "Millenniais' (Lack of) Attitude Problem: An Empirical Examination of Generational Effects on Work Attitudes," Journal of Business and Psychology (25:2), pp. 265-279. 
Lee, Y., Kozar, K. A., and Larsen, K. R. T. 2003. "The Technology Acceptance Model: Past, Present, and Future," Communications of the Association for Information Systems (12:1).

Legris, P., Ingham, J., and Collerette, P. 2003. "Why Do People Use Information Technology? A Critical Review of the Technology Acceptance Model," Information \& Management (40:3), pp. 191-204.

Magni, M., and Pennarola, F. 2008. "Intra-Organizational Relationships and Technology Acceptance," International Journal of Information Management (28:6), pp. 517-523.

Marangunić, N., and Granić, A. 2014. "Technology Acceptance Model: A Literature Review from 1986 to 2013," Universal Access in the Information Society (14:1), pp. 81-95.

Martin, C. A. 2005. "From High Maintenance to High Productivity," Industrial and Commercial Training (37:1), pp. 39-44.

Matthes, S., and Fülbeck, T. 2014. "Ex-Telekom-Manager Sattelberger Warnt: 'Die Jungen Menschen Laufen Den Falschen Göttern Nach," The Huffington Post, , November 8.

Nambisan, S., Agarwal, R., and Tanniru, M. 1999. "Organizational Mechanisms for Enhancing User Innovation in Information Technology," MIS Quarterly (23:3), pp. 365-395.

Niehaves, B., Gorbacheva, E., and Plattfaut, R. 2012. "Social Aspects in Technology Acceptance: Theory Integration and Development," in 2012 45th Hawaii International Conference on System Science (HICSS), , January, pp. 3149-3158.

Okoli, C. 2015. "A Guide to Conducting a Standalone Systematic Literature Review," Communications of the Association for Information Systems (37:1).

Park, S.-H. "Sunny," Lee, L., and Yi, M. Y. 2011. "Group-Level Effects of Facilitating Conditions on Individual Acceptance of Information Systems," Information Technology and Management (12:4), pp. 315-334.

Parment, A. 2013. Die Generation Y: Mitarbeiter der Zukunft motivieren, integrieren, führen, (2., vollst. überarb. u. erw. Aufl. 2013.), Wiesbaden: Gabler Verlag.

Petter, S., DeLone, W., and McLean, E. R. 2013. "Information Systems Success: The Quest for the Independent Variables," Journal of Management Information Systems (29:4), pp. 7-62.

Prensky, M. 2001a. "Digital Natives, Digital Immigrants Part 1," On the Horizon (9:5), pp. 1-6.

Prensky, M. 2001b. "Digital Natives, Digital Immigrants Part 2," On the Horizon (9:6).

Rowe, F. 2014. "What Literature Review Is Not: Diversity, Boundaries and Recommendations," European Journal of Information Systems (23:3), pp. 241-255.

Solnet, D., Kralj, A., and Kandampully, J. 2012. "Generation Y Employees: An Examination of Work Attitude Differences," The Journal of Applied Management and Entrepreneurship (17:3), pp. $36-54$.

Sorgenfrei, C., Ebner, K., Smolnik, S., and Jennex, M. E. 2014. "From Acceptance to Outcome: Towards an Integrative Framework for Information Technology," ECIS 2014 Proceedings.

Tapscott, D. 1998. Net kids: die digitale Generation erobert Wirtschaft und Gesellschaft. Growing up digital $<d t$. $>$, Wiesbaden: Gabler.

Tilvawala, K., Myers, M., and Sundaram, D. 2011. "Design Of Ubiquitous Information Systems For Digital Natives," PACIS 2011 Proceedings..

Twenge, J. M. 2010. "A Review of the Empirical Evidence on Generational Differences in Work Attitudes," Journal of Business and Psychology (25:2), pp. 201-210.

Twenge, J. M., and Campbell, S. M. 2008. "Generational Differences in Psychological Traits and Their Impact on the Workplace," Journal of Managerial Psychology (23:8), pp. 862-877.

Van der Heijden, H. 2004. "User Acceptance of Hedonic Information Systems," MIS Quarterly (28:4), pp. 695-704.

Venkatesh, V., Morris, M. G., Davis, G. B., and Davis, F. D. 2003. "User Acceptance of Information Technology: Toward a Unified View,” MIS Quarterly (27:3), pp. 425-478.

Webster, J., and Watson, R. 2002. "Analyzing the Past to Prepare for the Future: Writing a Literature Review," Management Information Systems Quarterly (26:2).

Williams, M. D., Dwivedi, Y. K., Lal, B., and Schwarz, A. 2009. "Contemporary Trends and Issues in IT Adoption and Diffusion Research," Journal of Information Technology (24:1), pp. 1-10.

Ziehe, T. 2013. "Mutmaßungen über die Tiefenwirkung der digitalen Vernetzung," in Digital Natives, W. Appel and B. Michel-Dittgen (eds.), Springer Gabler, Wiesbaden, pp. 205-212. 


\section{Copyright}

Copyright: (C) 2018 Hamelmann \& Drechsler. This is an open-access article distributed under the terms of the Creative Commons Attribution-NonCommercial 3.0 Australia License, which permits noncommercial use, distribution, and reproduction in any medium, provided the original author and ACIS are credited. 